\title{
Prediction of Discharge Destination after Neurological Rehabilitation in Stroke Patients
}

\author{
Matthias Frank ${ }^{a}$ Martin Conzelmann ${ }^{a}$ Stefan Engelter ${ }^{a, b}$ \\ ${ }^{a}$ Neurorehabilitation Unit, Geriatric Competence Center, Felix Platter-Spital, and \\ bStroke Unit, Neurological Department, University Hospital, Basel, Switzerland
}

\section{Key Words}

Cerebrovascular disease $\cdot$ Aging $\cdot$ Prognosis, stroke $\cdot$

Stroke outcome

\begin{abstract}
Background/Aims: Returning home is one of the most important aims of stroke patients when admitted to rehabilitation. Methods: A single-center prospectively ascertained database study was conducted. Results: Among 1,332 eligible patients (median age $=76.5$ years), $828(62.2 \%)$ returned home. Multiple logistic regression revealed 5 independent predictors: independent sitting balance, higher motor and social-cognitive functional independence measure subscores (all on admission to rehabilitation), living with a partner and younger age. The area under the curve (AUC) of this model was 0.86 (95\% confidence interval (Cl) 0.84 0.88 ). When age was excluded from the model, the AUC remained virtually the same (AUC $=0.85,95 \% \mathrm{Cl}=0.83-0.87$ ). Conclusion: The discharge destination could be predicted in a majority of patients with easily available parameters. Availability of a partner as well as parameters linked to severity of the neurological and functional deficit were both important. Age alone adds very little to the predictive power of these variables, therefore access to rehabilitation should not be denied on grounds of age.

Copyright $\odot 2010$ S. Karger AG, Basel
\end{abstract}

\section{Introduction}

Returning home is one of the most important aims of stroke patients when admitted to a rehabilitation unit. According to the International Classification of Function of the WHO [1] returning home belongs to the domain of participation. In this framework, participation is related to the domains of body function (the neurological impairment in stroke patients) and activity (level of impairment in activities of daily living).

In the literature, stroke severity and the level of basic activities of daily living as measured with appropriate scales are regarded as the most important predictors of recovery of function [2]. For discharge destination, several factors, like cognitive function, female gender and age, have been shown to be relevant in at least one study, but none of these factors has evolved in all studies [3].

Full recovery to prestroke function is often not achieved. Therefore, contextual factors (e.g. presence of a living partner) are important for the chance to return to the prior living situation. Thus, functional recovery is not the only variable determining the discharge destination.

The data have been presented as a poster at the 181st congress of the Swiss Neurological Society, Basle, Switzerland, Oct. 31, 2008.

\section{KARGER}

Fax +41613061234 E-Mail karger@karger.ch www.karger.com
Dr. Matthias Frank

Generisches Kompetenzzentrum, Abteilung für Neurorehabilitation Burgfelderstrasse 101

CH-4012 Basel (Switzerland)

Tel. +41 61326 4050, Fax +41 61326 4108,E-Mail matthias.frank@fps-basel.ch 

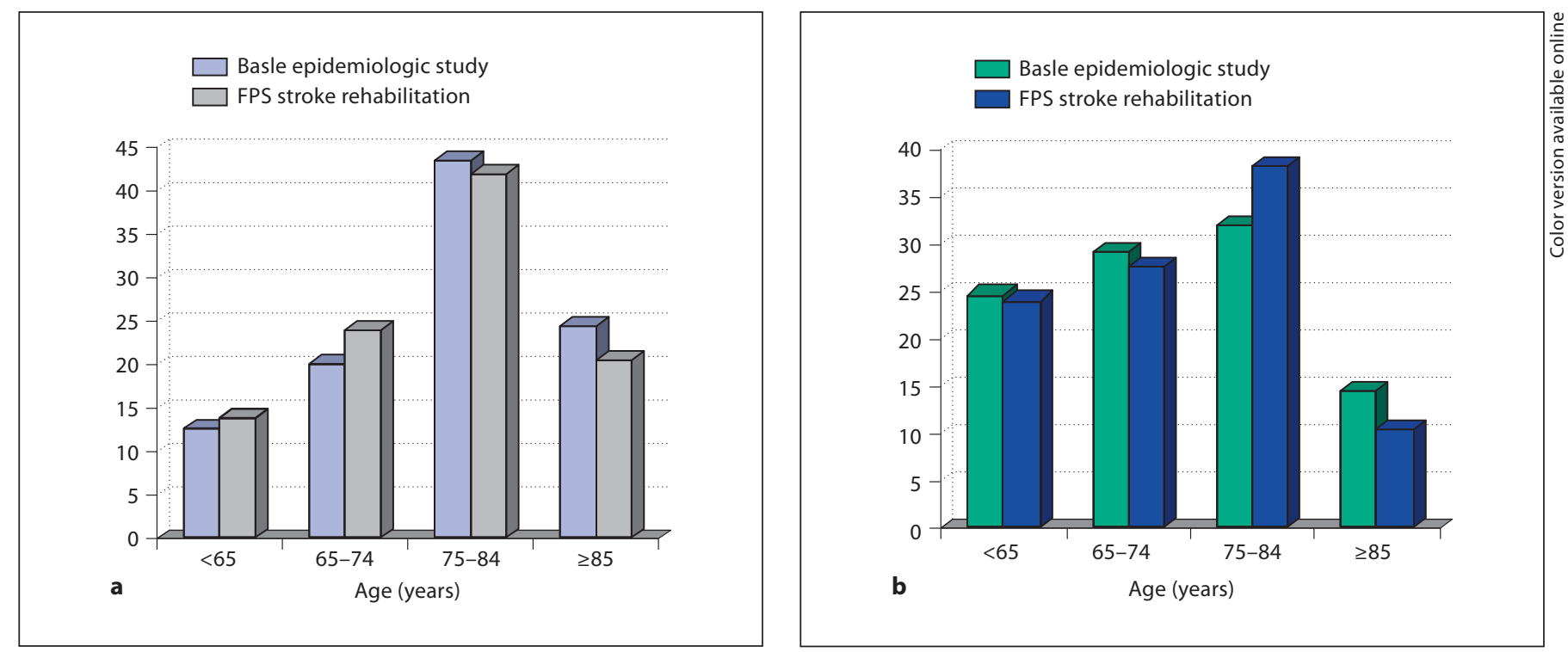

Fig. 1. Age distribution: Basle epidemiologic study 2002 and FPS stroke rehabilitation cohort 1996-2007. a Female patients. b Male patients.

We aimed to identify predictive variables covering all of the aforementioned neurological, functional and socioeconomic variables relevant to the outcome 'returning home after rehabilitation' in a large cohort of stroke patients treated in our rehabilitation unit. In particular we were interested in the predictive significance of the variable 'age'.

\section{Patients and Methods}

We conducted an analysis of prospectively ascertained data derived from a single-center database covering all patients consecutively admitted for neurological rehabilitation after acute ischemic or hemorrhagic stroke between 1996 and 2007. The neurological rehabilitation unit is part of a large community geriatric center and is co-led by a geriatrician and a neurologist. The rehabilitation unit provides stroke rehabilitation for all inhabitants of the canton Basle City, Switzerland $\left(37.1 \mathrm{~km}^{2} ; 188,015\right.$ inhabitants; Census 2002). It is closely connected to the Stroke Unit of the University Hospital of Basle by a defined 'stroke pathway'. In accordance with this pathway patients were admitted for rehabilitation without regard to age.

The following baseline parameters were ascertained: age [47], gender [8], living alone or with another person [9], need of professional help before stroke onset in activities of daily living [3], prior stroke [10], presence of hypertension [11], diabetes [12], tobacco use [13, 14], atrial fibrillation [13], carotid stenosis [15], presence of percutaneous endoscopic gastrostomy $[16,17]$ or urinary catheter and length of stay in acute care $[18,19]$ and in the rehabilitation unit. Based on a neurological examination on admission, the presence of aphasia [18, 20], dysarthrophonia [20], hemineglect [21, 22], hemianopia [23], independent sitting [5] or standing balance and walking ability (10 $\mathrm{m}$ unassisted with or without walking aid) were recorded. The clinical stroke syndrome was classified using the Oxfordshire community stroke project classification [24]. The stroke etiology was determined according to the Trial of Org 10172 in Acute Stroke Treatment criteria [25].

Within $72 \mathrm{~h}$ from admission, functional and cognitive abilities were assessed by the interdisciplinary team with the functional independence measure (FIM) [26]. The FIM is an 18-item assessment tool with a 7-point ordinal scale for each item and 2 main subscores (motor and cognitive) as well as 6 minor subscores (selfcare, continence, transfers, locomotion, communication and social cognition). FIM scorings were made by consensus in the interdisciplinary team and were repeated before discharge.

We excluded all patients with a length of stay in the rehabilitation unit $<5$ days $(\mathrm{n}=8)$.

For analysis, discharge destination was dichotomized into returning home and all other discharge destinations (i.e. death, transfer to a nursing home, readmission to acute care hospitals). The FIM total and subscores were divided by the number of items so that all values corresponded to the units of the 7-point ordinal scale with 1 indicating fully dependent and 7 fully independent patients. Age was analyzed as a continuous variable, but the data are presented per decade. Multiple logistic regression analyses were used to create predictive models. The accuracy of the models in predicting 'returning home after rehabilitation' was assessed by receiver operating characteristic curves using the predicted probabilities of the logistic regression. Data analysis was performed with SPSS package 12.0. 


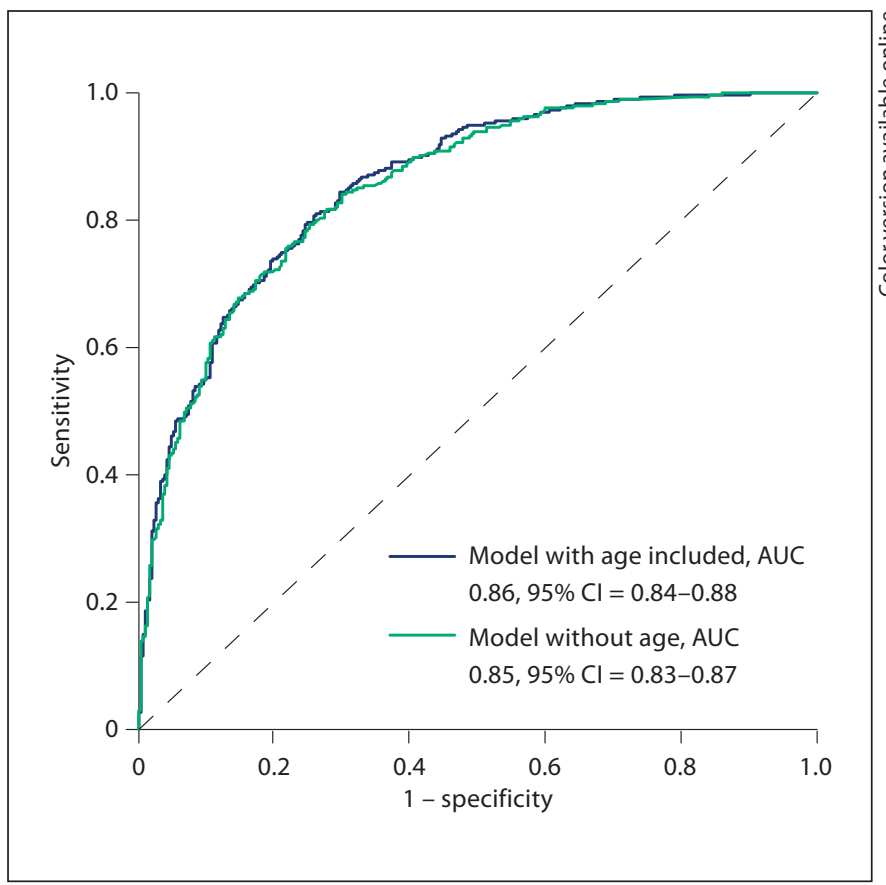

Fig. 2. ROC curves of the final model with and without age included.

\section{Results}

Of 1,340 patients, 1,332 (99\%) were eligible for the study. Stroke was confirmed by CT or MRI in 1,317 patients $(98.8 \%)$. The median age was 76.5 years; 248 patients $(18.6 \%)$ were under the age of 65 years. Approximately half of the patients were women (50.7\%), and 617 patients $(46.3 \%)$ were living alone prior to the stroke. The mean length of stay for in-patient rehabilitation was 50.9 \pm 37.0 days. Further baseline parameters are given in table 1. The age distribution in our patients was similar to that of the epidemiologic study of stroke in the canton Basle City in 2002 [27] (fig. 1).

After in-patient rehabilitation, 828 (62.2\%) of the patients returned home; 35 (2.6\%) died during rehabilitation, 318 (23.9\%) went to a nursing home and 151 (11.3\%) had other discharge destinations.

In univariate analysis, there was a significant positive correlation of return home with male gender, living with a partner, lower age, independent sitting or standing balance on admission and walking ability on admission. Negative correlations were found for atrial fibrillation, need of professional help before stroke, lower FIM total score, all FIM subscores and single items as well as pres- ence of aphasia, hemianopia, urinary catheter or percutaneous endoscopic gastrostomy.

In multiple logistic regression living with a partner, independent sitting balance on admission, motor and social-cognitive FIM subscores and age remained independent predictors (table 2). The area under the curve (AUC) of the final model was 0.86 [95\% confidence interval (CI) 0.84-0.88]. When age was excluded from the model, the AUC remained virtually the same $(\mathrm{AUC}=0.85,95 \% \mathrm{CI}$ 0.83-0.87) (fig. 2).

We also compared the percentage of patients discharged home with or without a living partner according to their admission motor and cognitive FIM (table 3). In all subgroups, the patients with a living partner were more likely to return home. The patients with the lowest cognitive FIM scores living alone had a very low chance of returning home even if they were less impaired in the motor FIM. In the patients with severe motor impairment, preserved cognitive abilities increased the chance of returning home regardless of the presence of a partner.

\section{Discussion}

Our analyses of a comprehensive stroke rehabilitation data bank showed the following main findings. Firstly, the presence of a living partner was the most important predictor of discharge 'home'. Secondly, independent sitting balance, and motor and sociocognitive abilities on admission were also important outcome predictors. Thirdly, the variable 'age' added little to the predictive power of the aforementioned variables with regard to 'returning home'.

The discharge destination 'returning home' was predicted by abilities in motor and social-cognitive domains on admission to rehabilitation. The motor subscore of the FIM measures basic activities of daily living function and corresponds very closely to the more commonly used Barthel index. The social-cognitive subscore comprises social interaction, problem solving and memory. Cognitive deficits in stroke patients admitted to rehabilitation are not necessarily exclusively stroke related. Pre-existing cognitive decline or delirium are potential confounders. In assessing individual patients' prognosis, these factors should be taken into account, which was not possible for our large cohort.

Our observation that independent sitting balance on admission predicted discharge destination 'home' confirms previous studies $[5,28]$. More importantly for clinical practice, this easily applicable test was as predictive 
Table 1. Baseline variables

\begin{tabular}{|c|c|c|c|c|}
\hline & $\begin{array}{l}\text { Discharged } \\
\text { home }(n=828)\end{array}$ & $\begin{array}{l}\text { Other discharge } \\
\text { destination }(\mathrm{n}=504)\end{array}$ & $\mathrm{p}$ & $\begin{array}{l}\text { Total } \\
(\mathrm{n}=1,332)\end{array}$ \\
\hline Median age, years & $74.6[25-96]$ & $79.0[32-99]$ & $<0.001$ & 76.5 [25-99] \\
\hline Female gender & $392(47.3)$ & $283(56.2)$ & 0.002 & $675(50.7)$ \\
\hline Living alone & $312(37.7)$ & $305(60.5)$ & $<0.001$ & $617(46.3)$ \\
\hline Need of professional help before stroke onset & $117(14.1)$ & $103(20.4)$ & 0.003 & $220(16.5)$ \\
\hline Prior stroke/TIA & $193(23.3)$ & $104(20.6)$ & 0.28 & $297(22.3)$ \\
\hline Hypertension & $609(73.6)$ & $363(72.0)$ & 0.57 & $972(73.0)$ \\
\hline Diabetes mellitus & $189(22.8)$ & $139(27.6)$ & 0.06 & $328(24.6)$ \\
\hline Atrial fibrillation & $178(21.5)$ & $143(28.4)$ & 0.005 & $321(24.1)$ \\
\hline Tobacco use & $224(27.1)$ & $92(18.3)$ & $<0.001$ & $316(23.7)$ \\
\hline \multicolumn{5}{|l|}{ Etiology } \\
\hline Small-vessel disease & $182(22.0)$ & $73(14.5)$ & 0.001 & $255(19.1)$ \\
\hline Cardioembolism & $178(21.5)$ & $141(28.0)$ & 0.008 & $319(23.9)$ \\
\hline Large-artery atherosclerosis & $171(20.7)$ & $87(17.3)$ & 0.14 & $258(19.4)$ \\
\hline Undetermined & $168(20.3)$ & $110(21.8)$ & 0.53 & $278(20.9)$ \\
\hline Hemianopia & $103(12.4)$ & $138(27.4)$ & $<0.001$ & $241(18.1)$ \\
\hline Hemineglect & $139(16.8)$ & $158(31.3)$ & $<0.001$ & $297(22.3)$ \\
\hline Aphasia & $189(22.8)$ & $158(31.3)$ & 0.001 & $347(26.1)$ \\
\hline Dysarthophonia & $311(37.6)$ & $262(52.0)$ & $<0.001$ & $573(43.0)$ \\
\hline Independent sitting balance & $784(94.7)$ & $334(66.3)$ & $<0.001$ & $1,118(83.9)$ \\
\hline Independent standing balance & $605(73.1)$ & $162(32.1)$ & $<0.001$ & $767(57.6)$ \\
\hline Independent walking ability $10 \mathrm{~m}$ & $415(50.1)$ & $93(18.5)$ & $<0.001$ & $508(38.1)$ \\
\hline OCSP Classification $(\mathrm{n}=1,175)$ & & & $<0.001$ & \\
\hline TACS & $50(6.0)$ & $133(26.4)$ & $<0.001$ & $183(13.7)$ \\
\hline PACS & $234(28.3)$ & $123(24.4)$ & 0.13 & $357(26.8)$ \\
\hline LACS & $254(30.7)$ & $103(20.4)$ & $<0.001$ & $357(26.8)$ \\
\hline POCS & $149(18.0)$ & $48(9.5)$ & $<0.001$ & $197(14.8)$ \\
\hline Not classified & $46(5.6)$ & $35(6.9)$ & 0.34 & $81(6.1)$ \\
\hline Percutaneous endoscopic gastrostomy & $90(17.9)$ & $40(4.8)$ & $<0.001$ & $130(9.8)$ \\
\hline Urinary catheter & $257(51.0)$ & $125(15.1)$ & $<0.001$ & $382(28.7)$ \\
\hline Acute length of stay $\pm S D$, days $(n=1,283)$ & $18.7 \pm 12.1$ & $21.7 \pm 15.5$ & $<0.001$ & $19.8 \pm 13.6$ \\
\hline Rehabilitation length of stay $\pm \mathrm{SD}$, days & $46.9 \pm 35.4$ & $57.6 \pm 38.5$ & $<0.001$ & $50.9 \pm 37.0$ \\
\hline Mean NIH Stroke Scale score \pm SD $(n=487)$ & $5.1 \pm 4.5$ & $9.6 \pm 7.4$ & $<0.001$ & $6.6 \pm 6.1$ \\
\hline Mean total FIM on admission \pm SD & $82.7 \pm 24.1$ & $49.7 \pm 25.8$ & $<0.001$ & $70.2 \pm 29.5$ \\
\hline Motor FIM subscore & $59.5 \pm 20.3$ & $33.8 \pm 20.7$ & $<0.001$ & $49.8 \pm 23.9$ \\
\hline Self-care & $27.6 \pm 9.2$ & $16.0 \pm 9.3$ & $<0.001$ & $23.2 \pm 10.8$ \\
\hline Continence & $10.6 \pm 3.7$ & $5.9 \pm 4.1$ & $<0.001$ & $8.8 \pm 4.5$ \\
\hline Transfer & $13.5 \pm 5.1$ & $7.7 \pm 5.3$ & $<0.001$ & $11.3 \pm 5.9$ \\
\hline Mobility & $7.7 \pm 4.0$ & $4.2 \pm 3.4$ & $<0.001$ & $6.4 \pm 4.1$ \\
\hline Communicative-cognitive subscore & $23.2 \pm 6.2$ & $15.9 \pm 7.6$ & $<0.001$ & $20.4 \pm 7.6$ \\
\hline Communicative & $9.6 \pm 2.7$ & $6.9 \pm 3.3$ & $<0.001$ & $8.6 \pm 3.2$ \\
\hline Social-cognitive & $13.6 \pm 3.9$ & $8.9 \pm 4.5$ & $<0.001$ & $11.8 \pm 4.7$ \\
\hline
\end{tabular}

Figures in parentheses are percentages and values in square brackets represent ranges. Ranges: total FIM = 18-126; motor FIM subscore $=13-91$; self-care $=6-42$; continence $=2-14$; transfer $=3-21$; mobility $=2-14$; communicative-cognitive subscore $=5-35$; communicative = 2-14; social-cognitive FIM subscore =3-21. TACS = Total anterior circulation stroke; PACS = partial anterior circulation stroke; LACS = lacunar stroke; POCS = posterior circulation stroke.

as the more complex FIM motor or sociocognitive subscores. On the other hand, lack of sitting balance cannot serve as a single criterion to deny rehabilitation: $20.6 \%$ $(44 / 214)$ of these patients ultimately went home.
The presence of a living partner is an important determinant for returning home after stroke [29, 30]. Our data indicate that residing with another person has a prognostic importance exceeding that of all other predictive vari- 
Table 2. Discharge home: univariate and multiple logistic regression

\begin{tabular}{|c|c|c|c|c|c|}
\hline & $\begin{array}{l}\text { Unadjusted } \\
\text { OR }\end{array}$ & $95 \% \mathrm{CI}$ & $\begin{array}{l}\text { Adjusted } \\
\text { OR }\end{array}$ & $95 \% \mathrm{CI}$ & Sig. \\
\hline Younger age (per decade) & 1.5 & $1.4-1.7$ & 1.4 & $1.2-1.6$ & 0.000 \\
\hline Male gender & 1.4 & $1.1-1.8$ & & & \\
\hline Living with another person & 2.5 & $2.0-3.2$ & 3.9 & $2.9-5.3$ & 0.000 \\
\hline Need of professional help before stroke onset & 1.6 & $1.2-2.1$ & & & \\
\hline Prior stroke/TIA & 1.2 & $0.9-1.5$ & & & \\
\hline Hypertension & 1.1 & $0.8-1.4$ & & & \\
\hline Diabetes mellitus & 0.8 & $0.6-1.0$ & & & \\
\hline Atrial fibrillation & 0.7 & $0.5-0.9$ & & & \\
\hline Tobacco use & 1.7 & $1.3-2.2$ & & & \\
\hline Etiology cardioembolism & 1.4 & $1.1-1.8$ & & & \\
\hline Hemianopia & 0.4 & $0.3-0.5$ & & & \\
\hline Hemineglect & 0.4 & $0.3-0.6$ & & & \\
\hline Aphasia & 0.6 & $0.5-0.8$ & & & \\
\hline Dysarthophonia & 0.6 & $0.4-0.7$ & & & \\
\hline Independent sitting balance & 9.1 & $6.4-12.9$ & 1.8 & $1.1-2.8$ & 0.014 \\
\hline Independent standing balance & 5.7 & $4.5-7.3$ & & & \\
\hline Independent walking ability $10 \mathrm{~m}$ & 4.4 & $3.4-5.8$ & & & \\
\hline OCSP classification TACS & 5.6 & $3.9-7.9$ & & & \\
\hline Percutaneous endoscopic gastrostomy & 0.2 & $0.1-0.3$ & & & \\
\hline Urinary catheter & 0.2 & $0.1-0.2$ & & & \\
\hline Motor FIM subscore (per unit increase) & 2.0 & $1.9-2.2$ & 1.6 & $1.4-1.8$ & 0.000 \\
\hline Social-cognitive FIM subscore (per unit increase) & 2.1 & $1.9-2.3$ & 1.6 & $1.4-1.8$ & 0.000 \\
\hline Motor FIM self-care subscore (per unit increase) & 2.1 & $1.9-2.2$ & & & \\
\hline Motor FIMcontinence subscore (per unit increase) & 1.7 & $1.6-1.8$ & & & \\
\hline Motor FIM transfer subscore (per unit increase) & 1.8 & $1.7-1.9$ & & & \\
\hline Motor FIM mobility subscore (per unit increase) & 1.6 & $1.5-1.7$ & & & \\
\hline Total FIM (per unit increase) & 2.3 & $2.1-2.5$ & & & \\
\hline Communicative FIM subscore (per unit increase) & 1.7 & $1.6-1.9$ & & & \\
\hline Cognitive-communicative FIM subscore & 2.1 & $1.9-2.3$ & & & \\
\hline
\end{tabular}

OCSP $=$ Oxfordshire community stroke project; TACS $=$ total anterior circulation stroke.

Table 3. Percentage of patients discharged home: motor and cognitive FIM subgroups and presence or absence of living partner

\begin{tabular}{|c|c|c|c|c|c|c|}
\hline \multirow[t]{3}{*}{ Social-cognitive FIM } & \multicolumn{6}{|l|}{ Motor FIM } \\
\hline & \multicolumn{2}{|l|}{$13-38$ points } & \multicolumn{2}{|l|}{$39-63$ points } & \multicolumn{2}{|l|}{ 64-91 points } \\
\hline & living alone & with partner & living alone & with partner & living alone & with partner \\
\hline $1-6$ points & $5(4 / 81)$ & $28(33 / 118)$ & $11(1 / 9)$ & $50(5 / 10)$ & $0(0 / 3)$ & $67(2 / 3)$ \\
\hline $7-14$ points & $28(34 / 120)$ & $55(72 / 129)$ & $49(55 / 113)$ & $84(94 / 112)$ & $70(65 / 93)$ & $94(89 / 95)$ \\
\hline $15-21$ points & $40(8 / 20)$ & $63(15 / 24)$ & $72(36 / 50)$ & $83(50 / 83)$ & $88(109 / 124)$ & $96(156 / 162)$ \\
\hline
\end{tabular}

ables. Compared to limitation in motor function, the presence of a partner corresponded to $>2$ points on the 7-point scale in motor FIM. Living alone was especially relevant in the presence of cognitive deficits.

Discharge Destination after Stroke Rehabilitation
'Age' was an independent predictor of stroke outcome in our patients. However, its impact on predicting discharge home was clinically negligible if added to the aforementioned prognostic variables $\left(\mathrm{AUC}_{\text {with age }}=0.86\right.$, 
$\left.\mathrm{AUC}_{\text {Without age }}=0.85\right)$. Functional recovery seems to be reduced in particular in very old stroke patients $[4,31]$. However, limited recovery was mainly restricted to those with severe strokes [32]. Thus, in line with Bagg et al. [6], our data indicate that age alone adds very little to the predictive power of other prognostic variables. Thus, decisions relating to stroke rehabilitation should not be based primarily on the patients' age.

A strength of our study was the single-center approach with a relatively large number of patients and the high rate of eligible patients ( $<1 \%$ exclusions). We are not aware of any other study of that size using a comprehensive data set combining neurological, functional and socioeconomic variables. Another advantage is the inclusion of stroke patients without age limits. In fact, the age distribution in our study closely resembled that of a population-based epidemiologic stroke study in our area [27]. These points reduce the likelihood of a selection bias and are in favor of a generalizablity of our results.

We are aware of the following limitations. (i) Apart from cardiovascular risk factors we did not measure comorbidity, which has been shown to be a prognostic fac- tor [5]. (ii) Information about basic activities of daily living and cognitive abilities prior to the stroke was not available. The use of the variable 'need for professional help before stroke onset' compensated this lack in part but did not include help by informal caregivers (e.g. family members).

In conclusion, the presence of a living partner was the strongest predictor of discharge home after stroke. Independent sitting balance as an easily applicable test on admission was as predictive as motor or sociocognitive abilities. The combination of the aforementioned variables enabled the prediction of discharge home with an accuracy of $83-87 \%$. The addition of 'age' increased the predictability by only $1 \%$. Thus, access to stroke rehabilitation should not be denied on grounds of age.

\section{Acknowledgements}

We thank A. Schötzau, Basle, Switzerland, for statistical advice and Clare Maguire, Basle, Switzerland, for assistance in preparing the manuscript.

\section{References}

1 World Health Organization: International Classification of Functioning, Disability and Health: ICF. Geneva, World Health Organization, 2001.

2 Warlow C, van Gijn J, Dennis M, et al. (eds): Stroke Practical Management, ed 3. Oxford, Blackwell, 2008, p $505 \mathrm{ff}$

-3 Meijer R, van Limbeek J, Kriek B, Ihnenfeldt D, Vermeulen M, de Haan R: Prognostic social factors in the subacute phase after a stroke for the discharge destination from the hospital stroke unit: a systematic review of the literature. Disabil Rehabil 2004;26:191197.

4 Kalra L: Does age affect benefits of stroke unit rehabilitation? Stroke 1994;25:346-351.

-5 Kwakkel G, Wagenaar RC, Kollen BJ, Lankhorst GJ: Predicting disability in stroke - a critical review of the literature. Age Ageing 1996;25:479-489.

6 Bagg S, Pombo AP, Hopman W: Effect of age on functional outcomes after stroke rehabilitation. Stroke 2002;33:179-185.

7 Meijer R, Ihnenfeldt DS, van Limbeek J, Vermeulen M, de Haan RJ: Prognostic factors in the subacute phase after stroke for the future residence after six months to one year: a systematic review of the literature. Clin Rehabil 2003;17:512-520.
8 Niewada M, Kobayashi A, Sandercock PA, Kaminski B, Czlonkowska A: Influence of gender on baseline features and clinical outcomes among 17370 patients with confirmed ischaemic stroke in the international stroke trial. Neuroepidemiology 2005;24:123-128.

-9 Nguyen TA, Page A, Aggarwal A, Henke P: Social determinants of discharge destination for patients after stroke with low admission FIM instrument scores. Arch Phys Med Rehabil 2007;88:740-744.

10 Jongbloed L: Prediction of function after stroke: a critical review. Stroke 1986;17:765776.

11 Blanco M, Castellanos M, Rodriguez-Yanez M, Sobrino T, Leira R, Vivancos J, et al: High blood pressure and inflammation are associated with poor prognosis in lacunar infarctions. Cerebrovasc Dis 2006;22:123-129.

$\checkmark 12$ Jorgensen H, Nakayama H, Raaschou HO, Olsen TS: Stroke in patients with diabetes: The Copenhagen Stroke Study. Stroke 1994; 25:1977-1984

13 Pinto A, Tuttolomondo A, Di Raimondo D, Fernandez P, Licata G: Risk factors profile and clinical outcome of ischemic stroke patients admitted in a department of internal medicine and classified by TOAST classification. Int Angiol 2006;25:261-267.
14 Liu X, Xu G, Wu W, Zhang R, Yin Q, Zhu W: Subtypes and one-year survival of first-ever stroke in Chinese patients: The Nanjing Stroke Registry. Cerebrovasc Dis 2006;22: 130-136.

15 Mead GE, Shingler H, Farrell A, O’Neill PA, McCollum CN: Carotid disease in acute stroke. Age Ageing 1998;27:677-682.

16 Dennis MS, Lewis SC, Warlow C: Effect of timing and method of enteral tube feeding for dysphagic stroke patients (FOOD): a multicentre randomised controlled trial. Lancet 2005;365:764-772.

$\checkmark 17$ Iizuka M, Reding M: Use of percutaneous endoscopic gastrostomy feeding tubes and functional recovery in stroke rehabilitation: a case-matched controlled study. Arch Phys Med Rehabil 2005;86:1049-1052.

18 Paolucci S, Antonucci G, Pratesi L, Traballesi M, Lubich S, Grasso MG: Functional outcome in stroke inpatient rehabilitation: predicting no, low and high response patients. Cerebrovasc Dis 1998;8:228-234.

19 Carod-Artal FJ, Medeiros MS, Horan TA, Braga LW: Predictive factors of functional gain in long-term stroke survivors admitted to a rehabilitation programme. Brain Inj $2005 ; 19: 667-673$ 
-20 Tilling K, Sterne JA, Rudd AG, Glass TA, Wityk RJ, Wolfe CD: A new method for predicting recovery after stroke. Stroke 2001;32: 2867-2873.

-21 Appelros P, Karlsson GM, Seiger A, Nydevik I: Prognosis for patients with neglect and anosognosia with special reference to cognitive impairment. J Rehabil Med 2003;35: 254-258.

-22 Appelros P, Nydevik I, Karlsson GM, Thorwalls A, Seiger A: Recovery from unilateral neglect after right-hemisphere stroke. Disabil Rehabil 2004;26:471-477.

-23 Patel AT, Duncan PW, Lai SM, Studenski S: The relation between impairments and functional outcomes poststroke. Arch Phys Med Rehabil 2000;81:1357-1363.

-24 Bamford J, Sandercock P, Dennis M, Burn J, Warlow C: Classification and natural history of clinically identifiable subtypes of cerebral infarction. Lancet 1991;337:1521-1526.
5 Adams HP Jr, Bendixen BH, Kappelle LJ, Biller J, Love BB, Gordon DL, et al: Classification of subtype of acute ischemic stroke: definitions for use in a multicenter clinical trial. TOAST. Trial of Org 10172 in Acute Stroke Treatment. Stroke 1993;24:35-41.

26 Linacre JM, Heinemann AW, Wright BD, Granger CV, Hamilton BB: The structure and stability of the Functional Independence Measure. Arch Phys Med Rehabil 1994;75: 127-132.

27 Gostynski M, Engelter S, Papa S, Ajdacic Gross V, Gutzwiller F, Lyrer P: Incidence of first-ever ischemic stroke in the Canton Basle-City, Switzerland: a population-based study 2002/2003. J Neurol 2006;253:86-91.
28 Brauer SG, Bew PG, Kuys SS, Lynch MR, Morrison G: Prediction of discharge destination after stroke using the motor assessment scale on admission: a prospective, multisite study. Arch Phys Med Rehabil 2008;89:10611065.

29 Massucci M, Perdon L, Agosti M, Celani MG, Righetti E, Recupero E, et al: Prognostic factors of activity limitation and discharge destination after stroke rehabilitation. Am J Phys Med Rehabil 2006;85:963-970.

30 Nguyen T-A, Page A, Aggarwal A, Henke P: Social determinants of discharge destination for patients after stroke with low admission FIM instrument scores. Arch Phys Med Rehabil 2007;88:740-744.

$>31$ Paolucci S, Antonucci G, Troisi E, Bragoni M, Coiro P, De Angelis D, et al: Aging and stroke rehabilitation: a case-comparison study. Cerebrovasc Dis 2003;15:98-105.

>32 Black-Schaffer RM, Winston C: Age and functional outcome after stroke. Top Stroke Rehabil 2004;11:23-32. 